\title{
DEVELOPMENT OF TV REMOTE JAMMER CIRCUIT USING 555 TIMER IC AND INFRARED LIGHT EMITTING DIODE
}

\author{
Umme Afruz \\ Department of Electronics and Telecommunication Engineering \\ Chittagong University of Engineering and Technology, Chittagong, Bangladesh
}

\begin{abstract}
In this modern era, remote control is used to operate electronic device wirelessly from any short distance. By using Tv remote jammer circuit, the remote control of the $\mathrm{TV}$ will be stopped. Anyone can prevent other for changing the specific channel of TV. He can watch his favorite channel without any interruption of anyone. Tv remote jammer is an IR jammer which is sending a constant IR pulse with the carrier frequency of the transmitter for confusing the infrared receiver in a TV by producing constant signal. As a result, the receiver will not accept the signal from the remote. Therefore, no action will be taken. It is designed by using IR led, 555 timer IC, capacitor, resistor, potentiometer etc. It is adjusted to produce $38 \mathrm{KHz}$ signal. This project is very cost effective and implementation is very easy. Anyone can easily make this circuit for jamming the tv remote in his home. The cost of this project is only $3 \$-4 \$$. This simple circuit has capability of blocking the communication established between Television and remote of the $t v$.
\end{abstract}

Keywords- Remote control, TV remote jammer, 555 Timer IC, IR led, Transistor.

\section{INTRODUCTION}

Remote control is one of the most important components of electronic device like television, DVD player, AC etc. Television has IR receiver which receives IR pulses or IR signals. These IR signals generated by remote of TV can't be detected by our human eye. Generally, the remote of TV emits pulse while pressing any button of remote. Because it consists of IR transmitter which emits a sequence of pulse for any button. IR receiver is placed on the TV which receives the pulses and identifies which button is pressed and take action very quickly. The IR pulses are generated by TV remote. In this project, a Tv jammer circuit is designed. It confuses the infrared receiver in a TV by producing constant signal which interferes with the remote-control signal. If the circuit is switched on, the TV will not receive any signal from the TV remote. It can help us to watch our favorite program and no one can change the channel or volume. The most important component used in this project is an infrared light. This infrared light is very cheap in cost which is invisible to human eye but anyone can see it using camera in phone or any other camera. This project is very cost effective because every component is very cheap and available to all of us.

\section{METHODOLOGY}

\section{A. Objective -}

The main objectives of this project is to jam the sensor of TV receiver at $38 \mathrm{KHz}$ frequency and to allow the user to jam the volume for avoiding irritation of loud noise or sound. It can prevent from turning on or off TV or changing any channel of TV.

\section{B. System Design and Implementation -}

The block diagram for this project is given below. At first, after implementation power supply is given to the circuit. Then, a constant IR pulses are generated which confuses the tv receiver by using the 555 timer and IR led. For this reason, the Tv receiver does not accept the signal from the remote and the communication between $\mathrm{TV}$ and remote will be stopped. 


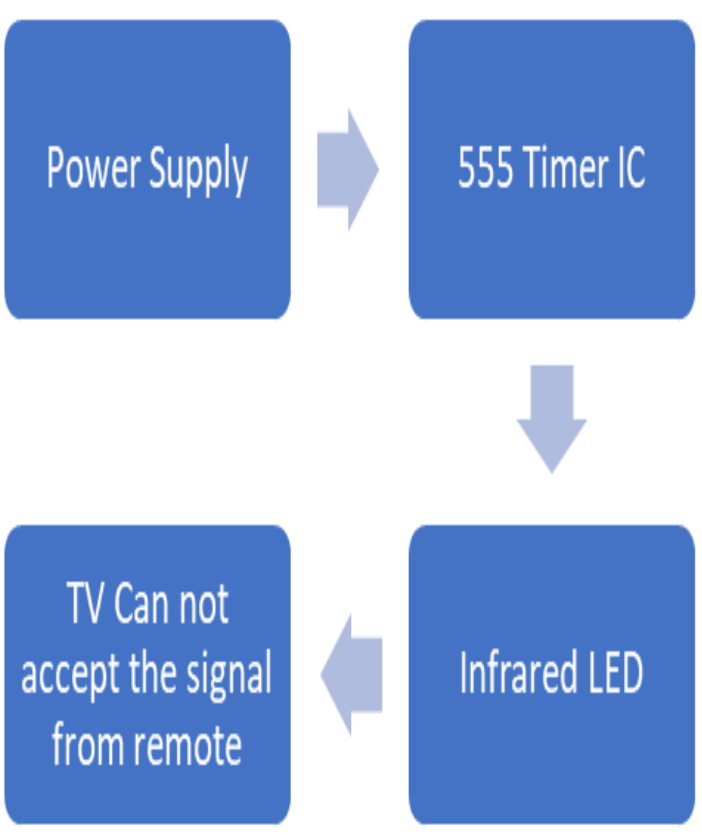

Fig. 1. Block Diagram of TV remote jammer circuit.

At first, the power supply is given by battery and the TV remote jammer circuit is switched on. Then it is placed in front of the television. By giving power supply, it generates the IR pulses and the television is confused. That's why, the television can't accept the signal from the remote.

From the flowchart, the working procedure of this project can be easily understood. This circuit must be tuned to $38 \mathrm{KHz}$ frequency for finding exact result. The IR pulses generated by this circuit confuses the TV receiver and the receiver side can not recognize the exact sequence from the remote. That's why the tv remote can't work and jamming is occurred.

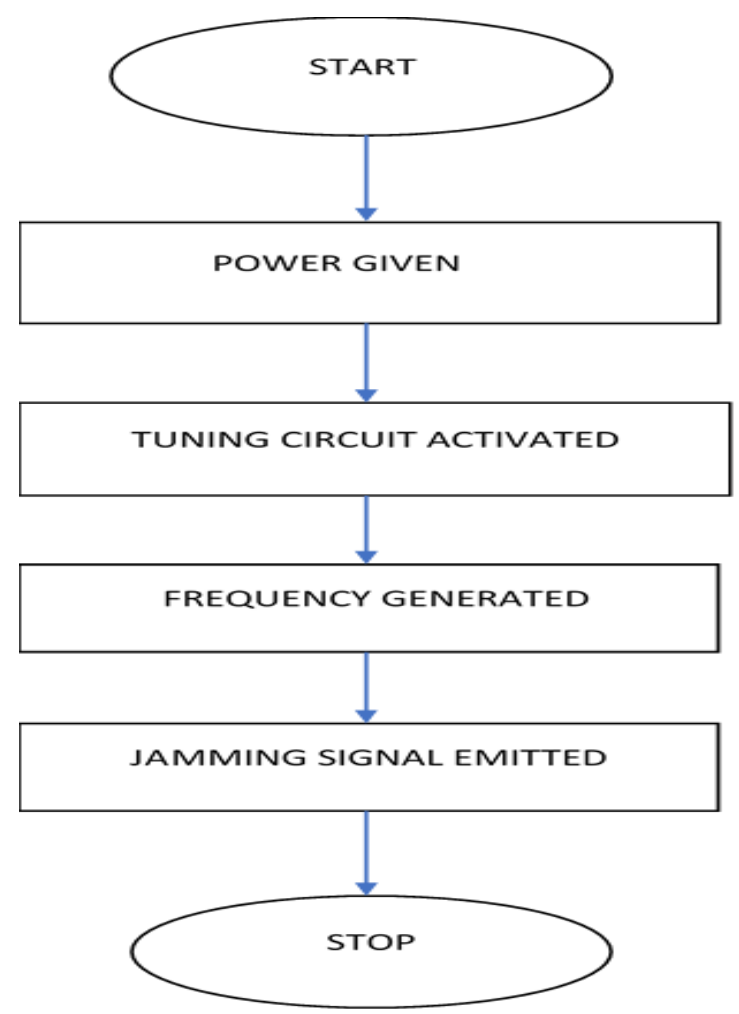

Fig. 2. Flow Chart of TV remote jamming circuit

\section{Hardware Implementation-}

\section{Infrared Led}

IR LED means infrared light emitting diode. It is solid state lighting device which can emit light in the infrared range. It allows for cheap and efficient production of infrared light which is invisible for human eyes but it can be visible by using camera.

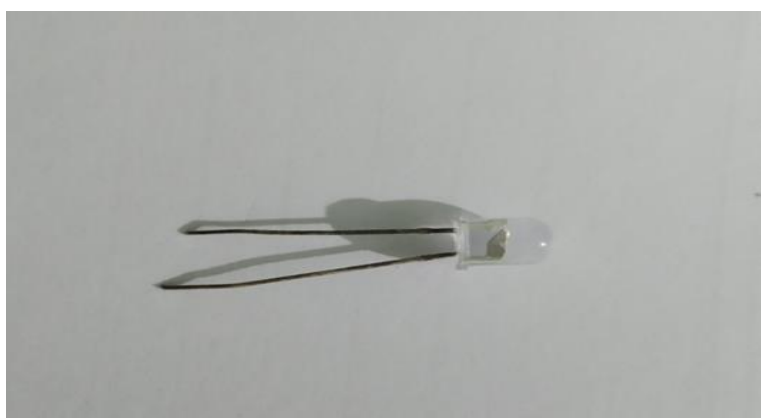

Fig. 3. Picture of IR LED 


\section{International Journal of Engineering Applied Sciences and Technology, 2020 \\ Vol. 4, Issue 11, ISSN No. 2455-2143, Pages 464-469 \\ Published Online March 2020 in IJEAST (http://www.ijeast.com)}

\section{Transistor}

Transistor BC547 is used for the amplifying current. The smaller amount of current in the base of transistor can produce a large amount of current in collector. It has three terminals. They are Base, Collector and Emitter. BC547 is NPN transistor which is used for the switching purpose.



Fig. 4. Picture of BC547 transistor

\section{Timer (IC)}

It is an integrated circuit which has three $5 \mathrm{k}$ ohm resistors and that's why its name is 555. It is used for pulse generation, time or oscillator operation. It has eight pins. It operates in 3 modes. They are A-stable, Mono-stable, Bi-stable mode. In this project, it works in A-stable mode. It means there is not stable level at the output. It operates from +5 volts to +18 volts power supply.

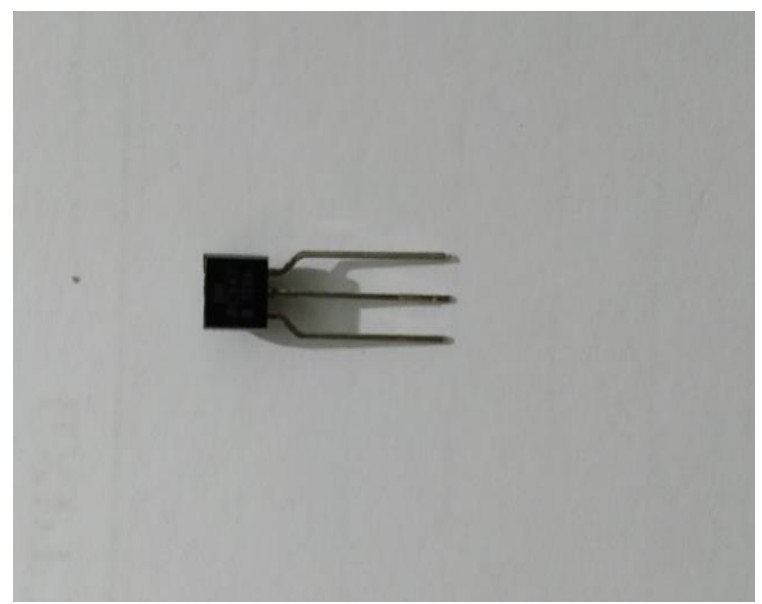

Fig. 5. Picture of 555 timer IC

\section{Potentiometer}

It is a three terminals resistor. It has rotating contact which forms an adjustable voltage divider. It works as a variable resistor. It is manually adjustable variable resistor to control the flow of electric current. In this experiment, 10k potentiometer is used.

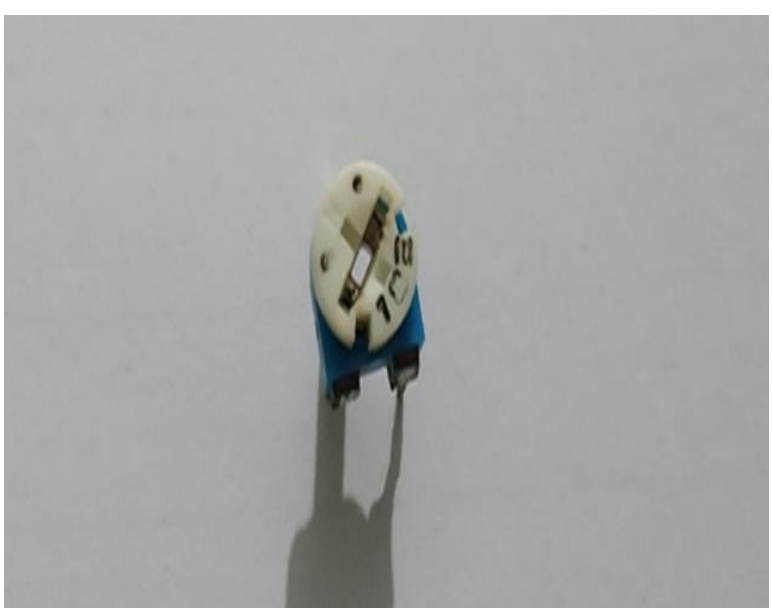

Fig. 6. Picture of $10 \mathrm{~K}$ potentiometer

\section{Capacitor}

It is the energy storage device which is passive electronic component with two terminals. It charges or discharges the electronic charge stored in it which can block the flow of DC and permit the flow of AC. In this experiment, $10 \mathrm{nF}$ capacitor is used.

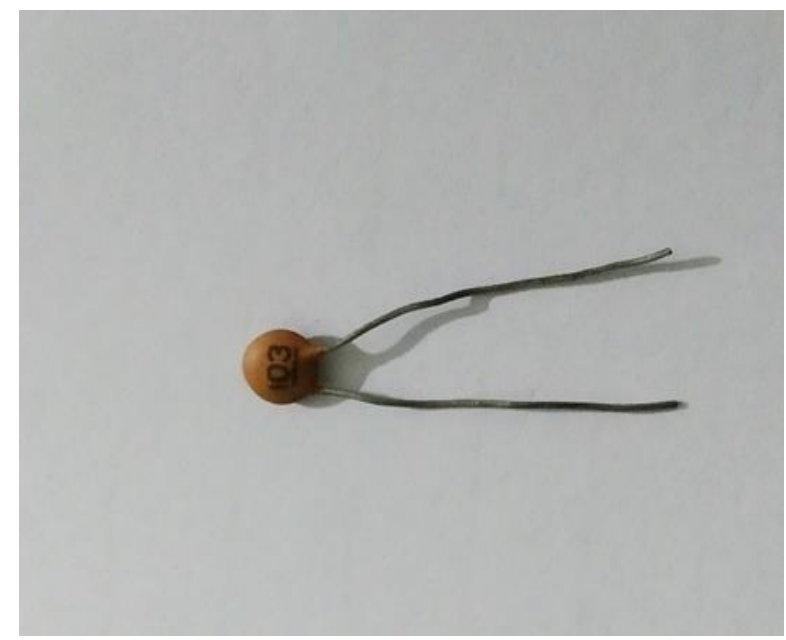

Fig. 7. Picture of $10 \mathrm{nF}$ capacitor 


\section{Diode}

A diode is a semiconductor device which acts as oneway switch for current. It allows to pass current in one direction and it has two terminal anode and cathode. In this experiment $1 \mathrm{~N} 4007$ diode is used. Instead of $1 \mathrm{~N} 4007,1 \mathrm{~N} 4148$ diode can be used in this circuit.



Fig. 8. Picture of 1N4007 Diode

\section{Working Procedure -}

The Tv remote is IR remote that emits a sequence of IR pulses by pressing a particular button of a TV remote. The transmitting component inside of the remote is a light emitting diode which is fixed at the pointing surface of the remote of the TV. The emitted pulses have unique configuration for each particular button of the remote. On the other hand, the TV set is programmed so that it can recognize all of the unique sequence and can take the action. As a result, the Tv remote responds to every call based on the different button on tv remote.

The proposed project is configured by using 555 timers which is arranged on A-stable mode. This Astable circuit can produce a sequence of pulses which transforms these voltage pulses into infrared radiation. This jammer circuit can be easily built in a breadboard. The $10 \mathrm{~K}$ potentiometer is adjusted to get the exact result from maximum distance. This circuit is operated using $9 \mathrm{~V}$ power supply or $9 \mathrm{~V}$ battery. The 555 -timer output is passed to the transistor to drive IR LED. The pulses which is generated by LED overlap the communication intervals between TV and TV remote. Because of this, there is no communication between transmitter and receiver and in this way, we can block the communication.

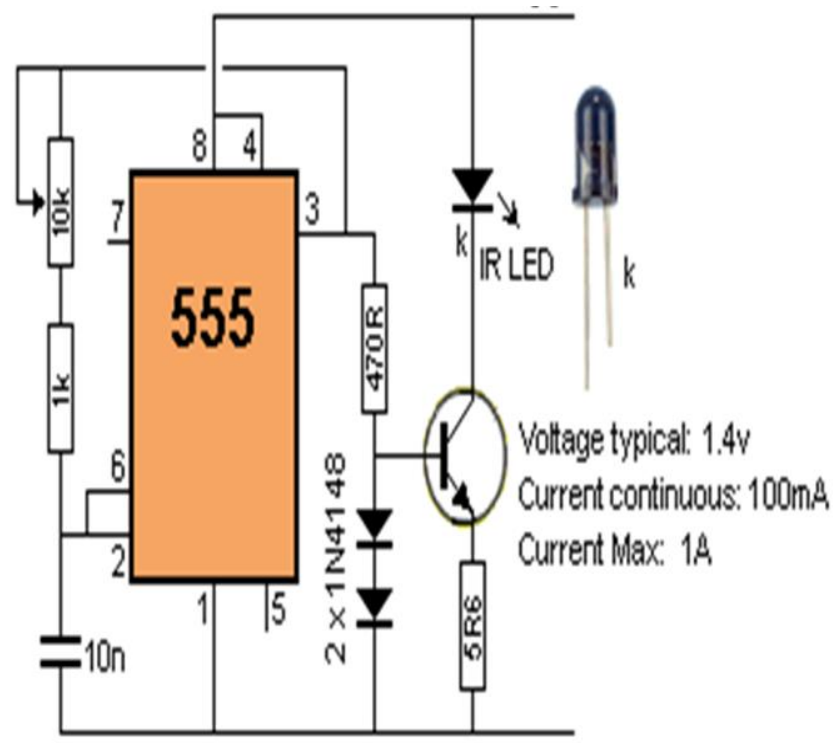

Fig. 9. Circuit diagram of TV remote jammer circuit

Most of the TV remote has operating frequency $38 \mathrm{KHz}$. That's why the IR pulse of $38 \mathrm{KHz}$ frequency confuses the TV receiver. In this project, the circuit is like an A- stable multi-vibrator by using 555-timer. All of the IR remotes operating in $38 \mathrm{KHz}$ frequency can be easily jammed by this project. In this project, the circuit is designed to produce $38 \mathrm{KHz}$ frequency and 555-timer is used.

\section{E. Algorithm for Operating the TV Remote}

\section{Control Circuit -}

Step.1: Connect 9v battery to this circuit.

Step.2: Adjust the 10k potentiometer for producing $38 \mathrm{KHz}$ signal.

Step.3: Press the TV remote button.

Step.4: Observe that the Tv will not receive any command from the Tv remote.

Step.5: Disconnect the battery from the circuit.

Step.6: Press the Tv remote button.

Step.7: Observe that $\mathrm{Tv}$ will receive the commands from remote. 


\section{International Journal of Engineering Applied Sciences and Technology, 2020 \\ Vol. 4, Issue 11, ISSN No. 2455-2143, Pages 464-469 \\ Published Online March 2020 in IJEAST (http://www.ijeast.com)}



Fig. 10. Hardware implementation of this project

\section{RESULT}

In this experiment, a TV remote jammer circuit is developed. It is designed by using 555 IC, BC 547 transistor, $10 \mathrm{k}$ variable resistor, three resistors $(1 \mathrm{k}$, 470 and $5.6 \mathrm{ohm}$ ), two 1N4007 diodes, IR LED and $10 \mathrm{nf}$ capacitor. After implementing all of these components, the circuit is placed in front of the TV.

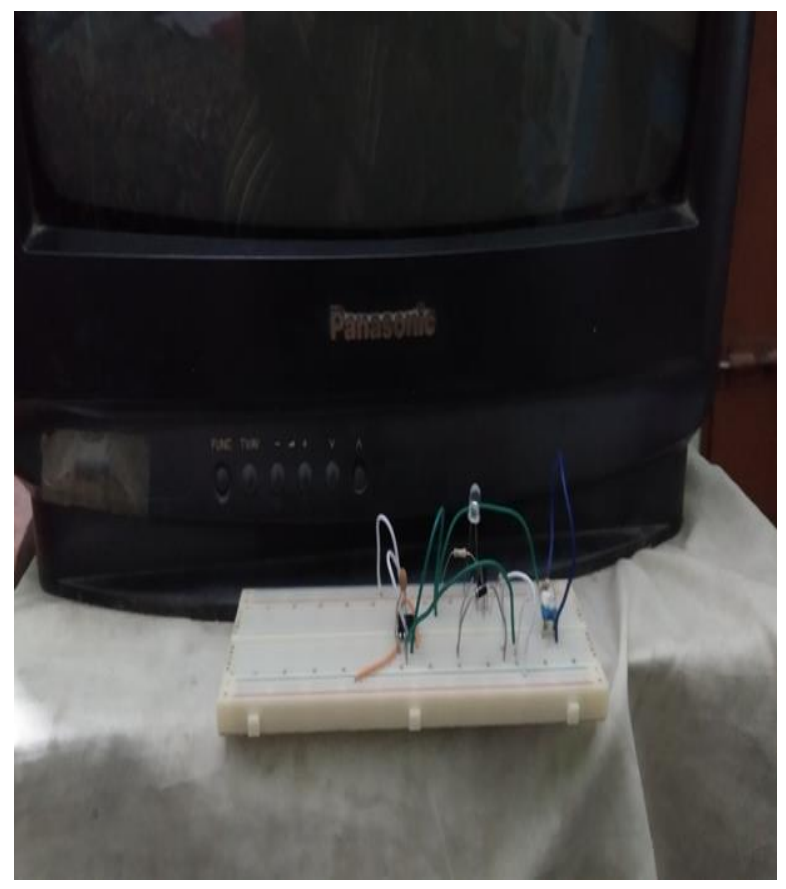

Fig. 11. The Tv remote jammer in front of TV before connecting power supply
Then, the power supply is given to the circuit by using 9 volts battery. when the button of remote is pressed, no action is taken, the communication between TV and remote is stopped. Because this circuit continuously generates constant signal pulses and the TV can't recognize the exact signal pulse that's why it can't response. So, we can use this project to jam the remote signal from tv remote, as a result no one can change the channel or change the volume of tv when someone watching tv. Again, this circuit does not affect the signal receiving capacity of TV.

\section{CONCLUSION}

In this paper, a $\mathrm{Tv}$ remote jammer circuit is successfully developed and its implementation is very easy. Again, it is very cost-effective project because the required components are very cheap. Maximum $4 \$$ will be needed to implement this circuit in home. This project helps us to watch our own favorite program on tv. No one can change the channel and can't on or off the tv by using the tv remote. We can implement this concept for any biggest issue in future. This circuit also helps not to allow any harmful change in any electronic devices. This circuit must be tuned to $38 \mathrm{KHz}$ frequency exactly for finding exact output which is the only limitation of this project.

The main Concept of this project is to design a circuit which can block the signal from tv remote by generating pulses from IR led. In future by using this concept, other home appliances like AC, remote controlled fan, remote controlled door can easily be jammed.

\section{ACKNOWLEDGEMENT}

I acknowledge the hard work and efforts of the researchers or experts who have contribution for developing different types of jammer circuit.

\section{REFERENCE}

[1] Alaparthi p. and Kumar R. R. (2013). Signal jamming and its modern applications, International Journal of Science and Research (IJSR), Vol. 2, No. 4, ISSN: 2319-7064.

[2] Krishnaiah N. R., Brundavani P. (2013). FPGA based wireless jamming networks, International Journal of Modern Engineering Research (IJMER), Vol. 3, No. 4.

[3] Gupta C., Garg N. (2014). Analysis of Jammer Circuit, International Journal of Engineering 


\section{International Journal of Engineering Applied Sciences and Technology, 2020}

Vol. 4, Issue 11, ISSN No. 2455-2143, Pages 464-469

Published Online March 2020 in IJEAST (http://www.ijeast.com)

Research and General Science, Vol. 2, No. 6,(pg758$61)$.

[4] Hussain A., Nazar N., Aqib A., Qamar S., Zia M., Mahmood H. (2014) Protocol-Aware Radio Frequency Jamming in $\mathrm{Wi}-\mathrm{Fi}$ and Commercial Wireless, Journal of communications and networks, Vol 16, No. 4, (pg397-406).

[5] Bhatia S.K., Sharma K., Chaudhary K., Singh D. (2015). Signal Jammer and Its Applications. International Journal of Electrical and Electronics Research. 3(2), (pg463-67).

[6] Oke A.O., Falohun A.S. and Adigun A.A. (2016). The Design and Implementation of a Mobile Phone Detector Device with a Frequency Jamming Feature, International Journal of Computer Applications, vol.143, iss.1, (pg15-19)

[7] Madara D.S., Ataro E. and Sitati S. (2016). Design and Testing of a Mobile Phone-Jammer, School of Engineering, Moi University, Kenya. Innovative Systems Design and Engineering, vol.7, no.7.

[8] Martins J.G., George N., Fidelia M. (2016). Design Considerations for a Dual Band GSM Signal Jammer Coupled to a Yagi-Uda Antenna, International Journal of Engineering Trends and Technology, Vol. 33, No. 7.

[9] Mahato S. and Vimala C. (2015) Cellular Signals Jamming System in 2G and 3G. International Journal of Advanced Research in Electrical, Electronics and Instrumentation Engineering, ISSN (Print): 2320 3765 .

[10] Azzam S., Hijazi A., Mahmoudy A. (2005). Smart Jammer for mobile phone systems, Zone of silence [cell phone jammer], Spectrum, IEEE, Vol.42, No.5, (pg677).

[11] Jisrawi A. (2010). GSM 900 Mobile jammer, Undergrad project, JUST, Vol.3, 2006, (pg89-91).

[12] Shah S.W., Babar, M.I., Arbab, M.N. (2008). Cell Phone Jammer, In Multitopic Conference, (pg34-39).

[13] Naresh P., Babu P.R., Satyaswathi K. (2013). Mobile Phone Signal Jammer or GSM, CDMA with pre-scheduled Time duration using ARM7, Inter. journal of science, Engineering and Technology Research, Volume 2, Issue 9, (pg148-152).

[14] https://www.electronicshub.org/tv-remotejammer-circuit

[15] https://www.555-timer-circuits.com/tv-remotecontrol-jammer.html
[16] https://www.electronicsforu.com/resouces/learnelectronics 